\title{
The effects of eight single microalgal diets on sex-ratio and gonad development throughout European flat oyster (Ostrea edulis L.) conditioning
}

\author{
Ricardo González-Araya, Virgile Quillien, René Robert*
}

\begin{abstract}
Ifremer, Département de Physiologie Fonctionnelle des Organismes Marins, Laboratoire de Physiologie des Invertébrés Marins, Centre Ifremer de Brest (Plouzané) et Station Expérimentale d'Argenton, 11 Presqu'île du Vivier, 29840 Argenton, France
\end{abstract}

\author{
*: Corresponding author : René Robert, tel.: + 33298892942 ; fax: + 33298892959 ; \\ email address : rene.robert@ifremer.fr
}

\begin{abstract}
:
To determine the effects of food quality on Ostrea edulis reproduction, European flat oysters were conditioned during two sets of experiments, carried out in spring and autumn, during 40 days at $19{ }^{\circ} \mathrm{C}$, in $50 \mathrm{I}$ transparent flow-through tanks, in triplicate, and fed constantly at $900 \mathrm{\mu m}^{3} \mathrm{\mu l}^{-1}$, with eight different types of microalgae. Four species were fed per group of trials: Isochrysis affinis galbana, Chaetoceros gracilis, Skeletonema marinoï, and Tetraselmis suecica were fed to flat oysters in the first set; whereas Rhodomonas salina, Thalassiosira weissflogii, Thalassiosira pseudonana, and Pavlova lutheri were provided during the second set of experiments. At the beginning and end of both conditioning periods, oysters were sampled and processed for histology analysis for each diet. Each oyster was classified for its sex and gonad development stage. Oysters fed S. marinoï and C. gracilis exhibited the highest ratio of hermaphrodites with 96 and $77 \%$ respectively, whereas those fed $T$. suecica showed the lowest hermaphrodite percentage, 59\%. When oysters were conditioned throughout the second set of experiments with four other species, oysters fed $R$. salina and $T$. weissflogii exhibited 83 and $87 \%$ of hermaphrodites. Regardless of the diet, a gonad development occurred during the first set of experiments with $\geq 60 \%$ ripe oysters (stage 3 ) and spawned oysters (stage 4). In the second set of trials, oysters fed $R$. salina and $T$. weissflogii were highly mature with $90 \%$ and $75 \%$ of stage 3 and stage 4 respectively; whereas those fed $P$. lutheri showed low maturation with only $17 \%$ of ripe oysters.
\end{abstract}

\section{Highlights}

We examine effects of eight single diets in gonadic development of $O$. edulis $>$ At the end of conditioning, large number of hermaphrodites were observed $-C$. gracilis, $S$. marinoï, $R$. salina and $T$. weissflogii are good diets $>T$. suecica and $P$. lutheri are poor diets for $O$. edulis broodstock conditionig

Keywords: Ostrea edulis ; Broodstock conditioning ; Gametogenesis ; Microalgal diets 


\section{Introduction}

From the 70s to the 80s two successive diseases affected Ostrea edulis production in France and the population dropped from 20,000 t to 1,000-1,500 t $\mathrm{y}^{-1}$ nowadays (Buestel et al., 2009). After diseases extension this situation was quite similar for most countries in Europe (Laing et al., 2005) where the flat oyster population has never recovered. In this context, except in some limited free diseases areas (e.g. Scotland, North, Ireland, Norway, and Denmark) flat oyster farming consists in improving oyster growth before the fateful limit of 3 years old or equivalent size and, accordingly, O. edulis production in Europe is constrained.

However, progress has been made in breeding for diseases resistance. Currently, a selective breeding program is, accordingly a possibility to enhance flat oyster farming as earlier shown for C. virginica (Ford et al., 1990). Such targeted genetic orientation, however, will not be feasible until the difficulty inherent to a lack of fully reliable methods in hatchery for this species is overcome. Indeed in the hatchery, unexplained mortalities have often been reported during larval rearing on day 8 and post-settlement (Laing et al., 2005). Hatchery methods are now relatively well known for many molluscs (e.g. Crassostrea gigas: Utting and Spencer, 1991, Ruditapes philippinarum: Helm and Pellizzato, 1990). Despite indisputable know-how, mainly due to pioneer works (Walne, 1974), the state of the art in hatchery rearing of $O$. edulis remains clearly insufficient to support reliable seed production, probably because of a lack of updated, detailed knowledge of the biology of this species.

We therefore focussed on the effects of food on O. edulis broodstock conditioning because in this larviparous species maternal effects have been shown to affect larval 
growth and survival (Berntsson et al., 1997). In most of molluscs reproduction, temperature has been considered as the key factor controlling reproduction in the natural surrounding (da Silva et al., 2009.) as well as in controlled condition (Wilson et al., 1996). Whereas the effect of food has been recognized more recently (Millican and Helm, 1994; Utting and Millican, 1997) the influence of diet quality, expressed as the species of microalgae delivered, on Ostrea edulis conditioning was however poorly known. We developed accordingly research in that field and showed that mixed diets increased fertility and improved subsequent larval development (González-Araya et al., 2012a). Moreover by means of physiological and biochemical studies we showed that Chaetoceros gracilis, Skeletonema marinö and Rhodomonas salina were highly ingested, assimilated, absorbed and well allocated in all flat oyster tissue including gonads (González-Araya et al., 2011, 2012b). But the effects of different microalgae diet on fine reproduction process (microscopic evolution of gonadic tissues) has not been analysed yet and the aim of the present work is accordingly to study the influence of food on sex dominance and gametogenesis evolution during conditioning in O. edulis.

\section{Material and methods}

\section{Broodstock conditioning}

We previously showed that a mixed diet was more efficient that single diets on flat oyster fecundity (expressed as number of larvae released: González-Araya et al., 2012a). To define the best microalgae combination we decided to perform trials with single diets to evaluate, firstly on a physiological point of view, which was the most ingested and 
digested microalgae, and secondly, through fatty acid and sterol transfer (from microalgae to oyster), which was the most assimilated diet in the gonads. To valid this approach a study of reproduction was carried out in parallel. Lastly, based on the knowledge of some specific biochemical component requirements, the two most physiologically and biochemically efficient microalgae should be associated hypothesising that they were the best diets for conditioning. This strategy, based on the evaluation of different single diets, allowed us to design 8 feeding trials; whereas based on bi-specific assemblage, 32 feeding trials, corresponding to an association of a diatom and a flagellate, were necessary, and thus, extremely difficult to manage. For such similar reason and to respect statistic procedures (triplicate condition per diet), it was necessary to perform such experiment at two different periods of the year.

A total of 720 flat oysters, originated from Brittany, were conditioned during 40 days at $19{ }^{\circ} \mathrm{C}$, in flow-through tanks and fed constantly at $900 \mu \mathrm{m}^{3} \mu \mathrm{l}^{-1}$. Eight different microalgae diets were delivered as single food to oysters, in two sets of experiments due to technical limitation (four microalgae tested within each set), to study feeding physiological needs and its incidence on reproduction process. All different algae were supplied at the same bio-volume. 18-month-old O. edulis $(\approx 5 \mathrm{~cm}$ length and $0.5 \mathrm{~g}$ meat dry weight), originated from Bay of Cancale (North Brittany, France) were distributed homogeneously, in February 2008, in translucent 50 L tanks (30 oysters per tank for an equivalent biomass), in triplicate for each of the four single diets used here. They were previously treated in chloramphenicol at $8 \mathrm{mg}^{-1}$ to limit any development of Vibrios and the initial spring condition corresponds to the oyster sampled prior to the distribution. The first experimental period was assessed using four microalgae: Isochrysis affinis galbana 
(T: CCAP 927/14), Chaetoceros gracilis ( $C_{g}$ : UTEX LB2658), Skeletonema marinoï $\left(S_{m:}\right.$ CCAP 66/4), Tetraselmis suecica ( $T_{s:}$ CCAP 1077/3).

In August 2008, O. edulis aged 18 months ( $\approx 5 \mathrm{~cm}$ length and $0.5 \mathrm{~g}$ flesh dry weight), originating from Bay of Quiberon (South Brittany, France) were submersed, at $5 \mathrm{~m}$ depth, for 1 month, in mesh bags tied to trestles in the Bay of Brest. They were then returned to the quarantine area of the Argenton hatchery, where they were maintained at $14{ }^{\circ} \mathrm{C}$ for an additional month, during which they were treated for a week with chloramphenicol. Thereafter, seawater temperature was increased by $1{ }^{\circ} \mathrm{C}$ weekly and, at beginning of October 2008, the flat oysters were transferred to translucent 50-1 tanks where they were distributed homogeneously (30 oysters per tank, corresponding to an equivalent biomass of $\approx 1 \mathrm{~kg}$ total weight and $16 \mathrm{~g}$ dry flesh weight). During this pre-conditioning period oysters were fed a mixed diet of T. Iso and C. gracilis used routinely in Argenton to feed $C$. gigas at different stages of development (Ben Kheder et al., 2010). The initial autumn condition corresponds to the oyster sampled prior to their distribution in individual tank. Triplicate tanks were set up for each of the four single diet species tested here during this second experimental period: Rhodomonas salina ( $R_{s:}$ CCAP 978/24), Thalassiosira weissflogii ( $T_{w}$ : CCAP 1085/1), Thalassiosira pseudonana ( $T_{p}$ : CCAP 1085/3) and Pavlova lutheri (P. CCAP $931 / 1$

At the end of both conditioning periods, oysters were sampled from each tank and processed for histological analysis.

\section{Histological analysis}


Each oyster was carefully opened, and a 5-mm thick section of tissue was excised parallel to the anterior-posterior axis between the labial palps and the posterior adductor muscle. They were thereafter fixed in Davidson's solution and embedded in paraffin. Tissue sections achieved in this manner contain gametes representative of the whole gonad. Finally, $5-\mu \mathrm{m}$ thick sections were stained with Harris's haematoxylin and eosin (Howard and Smith, 1983). Reproduction was studied on histological sections and each oyster was classified according to sex category and gonad development based on a scale detailed by da Silva et al. (2009). The sex was assigned as following: Indeterminate (I), when material had just collapsed or empty follicles are visible (Fig. 1a); male solely (M), when follicles contained only male gonadic material (Fig. 1b); female solely (F), when follicles contained only female gonadic material (Fig. 1c); hermaphrodite $(\mathrm{H})$, when female or male gonad material were observed, separately of prevalence sex (Fig. 1d-1e-1f).

Then a score of 0 to 4 was assigned to these figures with $0=$ inactive gonad and $4=$ empty due to spawning). Five stages per functional sex of gonad development were considered as following:

- Inactive or resting gonad (0) (Fig. 1a): no evidence of ripe gametes development. The gonad is dilated and empty; follicles are located between mantle and digestive gland surrounded by abundant connective tissue.

- Early gametogenesis (1) (Fig. 1b): gonad follicles are more spread into the connective tissue with ovogonia and spermatogonia mostly attached to the follicle wall. In the male part, there are primary and secondary spermatocytes. In the female part, developing oocytes are attached to developing lines.

- Advanced gametogenesis (2) (Figs. 1c, 1d): gonad follicles are larger than in the previous phase, but connective tissue is still present. In the male section the 
development of few spermatogonia still occurred, but sparmatocytes and spermatid balls are dominant; in the female section, oocytes in vitellogenesis are dominant, while oocytes in post-vitellogenesis are sparse.

- Ripe gonad (3) (Figs. 1e, 1f): juxtaposed large follicles occupied the entire area between the mantle and digestive gland. Both male and functional female developing lines, follicles contained gametes, abundant spermatozoa balls and mature oocytes.

- Spawned (4): gonad follicles are smaller than in the previous phase. Gametes have been released and residual mature ooocytes and sperm balls could be observed in the follicle lumen. Phagocytes are often observed in the follicle lumen.

When hermaphrodites were detected, the subcategory of one sex predominance was not considered, because the aim of this experience was to study the overall effects of monospecific diets on gonadic development without detailing hermaphrodite aspects.

\section{Statistical analysis}

Comparison of oyster distribution in gonad condition classes (sex and gonad development) between conditioning diet and sex category were analyzed using a Chisquare test of independence. The same procedure was applied to test the association of gonad condition classes and season of conditioning, in which the sex or gonad development was organized into columns, and the O. edulis diets into rows. Statistical analysis was performed using the software STATISTICA (version 8.0). Differences were considered statistically significant when $p$ values were lower than 0.05 . 


\section{Results}

Oysters fed S. marinoï and C. gracilis during spring conditioning exhibited the highest percentage of hermaphrodites with 96 and 77\% respectively; whereas those fed T. suecica showed the lowest hermaphrodites ratio (59\%: Table 1). In autumn when oysters were fed R. salina and T. weissflogii 83 to $87 \%$ hermaphrodites were recorded whereas those fed T. pseudonana and P. lutheri led to 58 and 33\% hermaphrodites respectively. However, the highest proportion of female was founded in oysters fed P. lutheri $(33 \%)$ and the lowest in those fed $S$. marinö̈ (0\%: Table 1). Except in oysters fed $R$. salina, male was observed in all samples (Table 1). High percentages of indeterminate were observed in the two initial conditions, spring (21\%) and especially autumn (67\%) as well as in oysters fed T. suecica (24\%) and P. lutheri (23\%).

Regardless diet and season, gonadic development occurred. At the end of spring conditioning the marked differences were observed $\left(\chi^{2}=6.02 ; \mathrm{df}=4 ; \mathrm{P}<0.001\right)$ with more than $60 \%$ of oysters were ripe (stage 3) or have recently spawned (stage 4) (Fig. 2). The highest value of recently spawned individuals was recorded in oysters fed T-Iso; whereas those fed S. marinoi and C. gracilis showed the highest values of ripe gonads (70 and 55\% respectively). Those receiving T. suecica and T-Iso exhibited $38 \%$ and $31 \%$ of ripe gonads respectively. Apart from initial condition, early gametogenesis was only observed in oysters fed T. suecica (3\%: $\left.\chi^{2}=26.17 ; \mathrm{df}=1 ; \mathrm{P}=0.048\right)$ (Fig. 2).

In autumn, the highest values of stages 3 and 4 were observed in oysters fed R. salina (> 90\%) and T. weissflogii $(>75 \%)$ whereas the lowest value was observed for those fed $P$. lutheri $\left(17 \%: \chi^{2}=82.14 ; \mathrm{df}=2 ; \mathrm{P}<0.001\right)$. Initial and advanced gametogenesis (stages 1 
and 2) were observed in oysters regardless diets, whereas stage 0 (indeterminate) was undetected in oysters fed R. salina. At the initiation of this fall conditioning period, $33 \%$ of recently spawned oysters and $67 \%$ of indeterminate were found $\left(\chi^{2}=8.85\right.$; $\mathrm{df}=4$; $\mathrm{P}=$ $0.048)$.

\section{Discussion}

At the end of conditioning periods, most of $O$. edulis examined in spring and autumn were hermaphrodites, excepted for initial condition in autumn with $67 \%$ of indeterminate. The presence of large number of hermaphrodites, as well as small percentage of males and females may indicate that, gametogenic phase followed the next one without complete resorption as already reported (Siddiqui and Ahmed, 2002).

Whereas temperature effects on gonad development and spawning are nowadays well known (e.g. Mann, 1979; Helm et al., 2004), the influence of food on the reproductive pattern of bivalves which includes growth, maturation, spawning, resorption and resting period are less documented (Kang et al., 2000). The occurrence of greater proportion of ripe gonad (stage 3) and spawning (stage 4) in oysters fed C. gracilis, S. marinoi, R. salina and T. weissfloggi indicate that gametogenesis was more rapid than with other diets used. This result could be explained by specific biochemical allocations in gonads. Despite, the absence of correlation between fatty acids concentration and gonadic development (González-Araya et al., 2011) it has been showed that cholesterol concentration in $C$.

gracilis and S. marinoi were higher than in T-Iso and T. suecica. For autumn conditioning, similar concentrations of brassicasterol and cholesterol in gonads of oysters fed R. salina and T. weissflogii have been already reported (González-Araya et al., 2012a). The role of 
cholesterol in mollusks gametogenesis is still unknown but bivalves have a limited capacity for cholesterol synthesis or bioconversion of phytosterols into cholesterol (Napolitano et al., 1993; Kanazawa, 2001). Phytosterols present in oysters reflect accordingly ingested microalgae. Different microalgae synthesize specific phytosterols (Palacios et al., 2007): for example, brassicasterol has been found in high concentrations (90\%) in Isochrysis sp. (Volkman et al., 1981), whereas 24-methylenecholesterol and also cholesterol could be recorded in diatomophyceae such as Chaetoceros sp., Skeletonema sp., Thalassiosira sp. (Soudant et al., 1998; González-Araya et al., 2012b).

On eight microalgae commonly used in hatchery four of them (C. gracilis, S. marinö̈, $R$. salina and T. weissflogii) promoted a better and faster $O$. edulis gonadic development. In contrast, oysters fed T. suecica and P. lutheri showed the lowest gametogenesis and are accordingly not recommended for broodstock conditioning. T-Iso occupied an intermediate position and combined with a diatom could represent an efficient diet for $O$. edulis broodstock conditioning but never as single diet.

\section{Acknowledgments}

This work could not have been completed without the technical support of the team at the Argenton Ifremer station -C. Mingant, I. Quéau and L. Lebrun- all of whom we wish to thank. We are also grateful to the Universidad de Los Lagos (MECESUP-ULA 03/02), which contributed to the partial funding of a PhD grant for the first author. This work was carried out during the SETTLE project and was partially funded by FP7/2007-2013 under agreement no. 222043. 


\section{References}

Ben Kheder, R., Quéré, C., Moal, J., Robert, R., 2010. Effect of nutrition on Crassostrea gigas larval development and the evolution of physiological indices. Part A: quantitative and qualitative diet effects. Aquaculture 305, 165-173.

Berntsson, K.M., Jonsson, P.R., Wängberg, S.Å., Carlsson, A.S., 1997. Effects of broodstock diets on fatty acid composition, survival and growth rates in larvae of the European flat oyster, Ostrea edulis. Aquaculture, 154, 139-153.

Buestel, D., Ropert, M., Prou, J., Goulletquer, P., 2009. History, status and future of oyster culture in France. Journal of Shellfish Research 28 (4), 813-820.

da Silva, P.M., Fuentes, J., Villalba, A., 2009. Differences in gametogenic cycle among strains of the European flat oyster Ostrea edulis and relationship between gametogenesis and bonamiosis. Aquaculture 287, 253-265.

Ford S.E., Figueras A.J., Haskin H.H., 1990. Influence of selective breeding, geographic origin, and disease on gametogenesis and sex ratios of oysters, Crassostrea virginica, exposed to the parasite Haplosporidium nelsoni (MSX). Aquaculture 88 (3-4), 285301.

González-Araya, R., Quéau, I., Quéré, C., Moal, J., Robert, R., 2011. A physiological and biochemical approach to selecting the ideal diet for Ostrea edulis (L.) broodstock conditioning (Part A). Aquaculture Research 42, 710-726.

González-Araya, R., Petton, B., Mingant, C., Robert, R, 2012a. Influence of diet assemblage on Ostrea edulis broodstock conditioning and subsequent larval development. Aquaculture 364-365, 272-280.

González-Araya, R., Lebrun, L., Quéré, C., Robert, R., 2012a. The selection of the ideal diet for Ostrea edulis (L.) broodstock conditioning (part B). Aquaculture 362-363, $55-66$.

Helm, M.M., Pellizzato, M., 1990. Riproduzione ed allevamento in schiuditoio della specie Tapes philippinarum. p 117-140. In G. Allessandra (ed) Tapes philippinarum: Biologia e Sperimentazione. Ente Svillupo Agricolo Veneto, Venice, Italy, 299pp.

Helm, M.M., Bourne, N., Lovatelli, A., 2004. Hatchery culture of bivalves. A practical manual. FAO, Fisheries Technical Paper No.471, Rome, 200 pp.

Howard, D.W., Smith, C.S., 1983. Histological techniques for marine bivalve mollusks. National Marine Fisheries Service, Woods Hole, MA No. NOAA-TM-NMFS-F/NEC-25. Springfield: Northeast Fisheries Center.

Kanazawa, A., 2001. Sterols in marine invertebrates. Fisheries Science 67, 997-1007.

Kang, C.K., Park, M.S., Lee, P.Y., Choi, W.J., Lee, W.C., 2000. Seasonal variations in condition, reproductive activity, and biochemical composition of the pacific oyster, Crassostrea gigas (Thumberg), in suspended culture in two coastal bays of Korea. Journal of Shellfish Research 19, 771-778.

Laing, I., Walker, P., Areal, F., 2005. A feasibility study of native oyster (Ostrea edulis) stock regeneration in the United Kingdom. CARD Project FC1016. Native oyster stock regeneration: a review of biological, technical and economic feasibility. $95 \mathrm{pp}$.

Mann, R., 1979. Some biochemical and physiological aspects of growth and gametogenesis in Crassostrea gigas and Ostrea edulis grown at sustained elevated temperatures. Journal of Marine Biological Association of U.K. 59, 95-110.

Millican, P.F., Helm, M.M., 1994. Effects of nutrition on larvae production in the European flat oyster, Ostrea edulis. Aquaculture 23, 83-94. 
Palacios, E., Racotta,I.S., Arjona, O., Marty, Y., Le Coz, J.R., Moal, J., Samain J.F., 2007. Lipid composition of the pacific lion-paw scallop, Nodipecten subnodosus, in relation to gametogenesis: 2. Lipid classes and sterols. Aquaculture 266, 266-273.

Siddiqui, G., Ahmed, M., 2002. Gametogenic patterns of the larviparous oyster Ostrea nomades from Karachi, Pakistan (northern Arabian Sea). Aquaculture Research 33, 1049-1058.

Soudant, P., Le Coz, J.R., Marty, Y., Moal, J., Robert, R., Samain, J.F. 1998. Incorporation of microalgae sterols by scallop Pecten maximus (L.) larvae. Comparative Biochemistry and Physiology 119A, 451-457.

Utting, S.O., Millican, P.F., 1997. Techniques for the hatchery conditioning of bivalve broodstock and the subsequent effect on egg quality and larval viability. Aquaculture 155, 45-54.

Utting, S.D., Spencer, B.E., 1991. The hatchery culture of bivalve mollusc larvae and juveniles, Vol. 68. Laboratory of Ministry of Agriculture, Fisheries and Food, Directorate of Fisheries Research, Lowestoft, UK, 31pp.

Volkman, J.K., Smith, D.J., Eglinton, G.E., Forsberg, T.E.V., Corner, D.S., 1981. Sterol and fatty acid composition of four marine haptophycean algae. Journal of Marine Biological Association of U.K., 61 (2), 509-527.

Walne, P.R., 1974. Culture of bivalve molluscs, 50 years experience at Conwy. Fishing News Book, 189pp.

Wilson, J.A., Chaparro, O.R., Thompson, R.J., 1996. The importance of broodstock nutrition on the viability of larvae and spat in the Chilean oyster Ostrea chilensis. Aquaculture 139, 63-75. 


\section{List of tables:}

Table 1. Effects of microalgal diets fed Ostrea edulis on sex repartition classes (\%).

\section{List of figures:}

Figure 1. Microphotographies of histological sections of Ostrea edulis, showing the gonad area of different sex categories. a: Indeterminate gonad. b: Male gonad solely, ripe gonad. c: Female gonad solely, ripe gonad. d: Hermaphrodite with both sex equally represented, ripe ooocytes, initial and advanced spermatogenesis observed. e: Hermaphrodite predominantly male, ripe ooocytes, partially spawning of spermatozoa balls observed. f: Hermaphrodite predominantly female, ripe gonad, ripe ooocytes, spermatozoa balls observed. In all plates male gonads are coloured in blue whereas females are dyed in pink.

Figure 2. Effects of microalgal diets fed Ostrea edulis on gametogenesis evolution: stage 0: Inactive gonad. 1: Early gametogenesis. 2: Advanced gametogenesis. 3: Ripe gonad. 4: Spawned.

A: oysters fed T (I. aff. galbana), $C_{g}$ (C. gracilis), $S_{m}\left(S\right.$. marinoi), $T_{s}(T$. suecica $)$.

B: oysters fed $R_{s}$ (R. salina), $T_{w}$ (T. weissflogii), $T_{p}$ (T. pseudonana) and $P_{l}(P$. lutheri).

I: For both graphs means Initial condition, just before conditioning.

Table 1.

\begin{tabular}{|c|c|c|c|c|c|c|c|c|c|c|}
\hline \multirow[t]{3}{*}{ Sex category } & \multirow{2}{*}{\multicolumn{5}{|c|}{ Spring conditioning }} & & & & & \\
\hline & & & & & & \multicolumn{5}{|c|}{ Autumn conditioning } \\
\hline & $\mathrm{I}$ & $\mathrm{T}$ & $C_{g}$ & $S_{m}$ & $T_{s}$ & $\mathrm{I}$ & $\mathrm{R}_{s}$ & $T_{w}$ & $T_{p}$ & $P_{l}$ \\
\hline Indeterminate & 21.4 & 0.0 & 4.5 & 0.0 & 24.1 & 66.7 & 0.0 & 6.5 & 12.1 & 23.3 \\
\hline Male & 14.3 & 15.4 & 13.6 & 4.3 & 10.3 & 16.7 & 0.0 & 3.2 & 6.1 & 10.0 \\
\hline Female & 0.0 & 15.4 & 4.5 & 0.0 & 6.9 & 16.7 & 17.2 & 3.2 & 24.2 & 33.3 \\
\hline Hermaphrodite & 64.3 & 69.2 & 77.3 & 95.7 & 58.6 & 0.0 & 82.8 & 87.1 & 57.6 & 33.3 \\
\hline
\end{tabular}


Figure 1

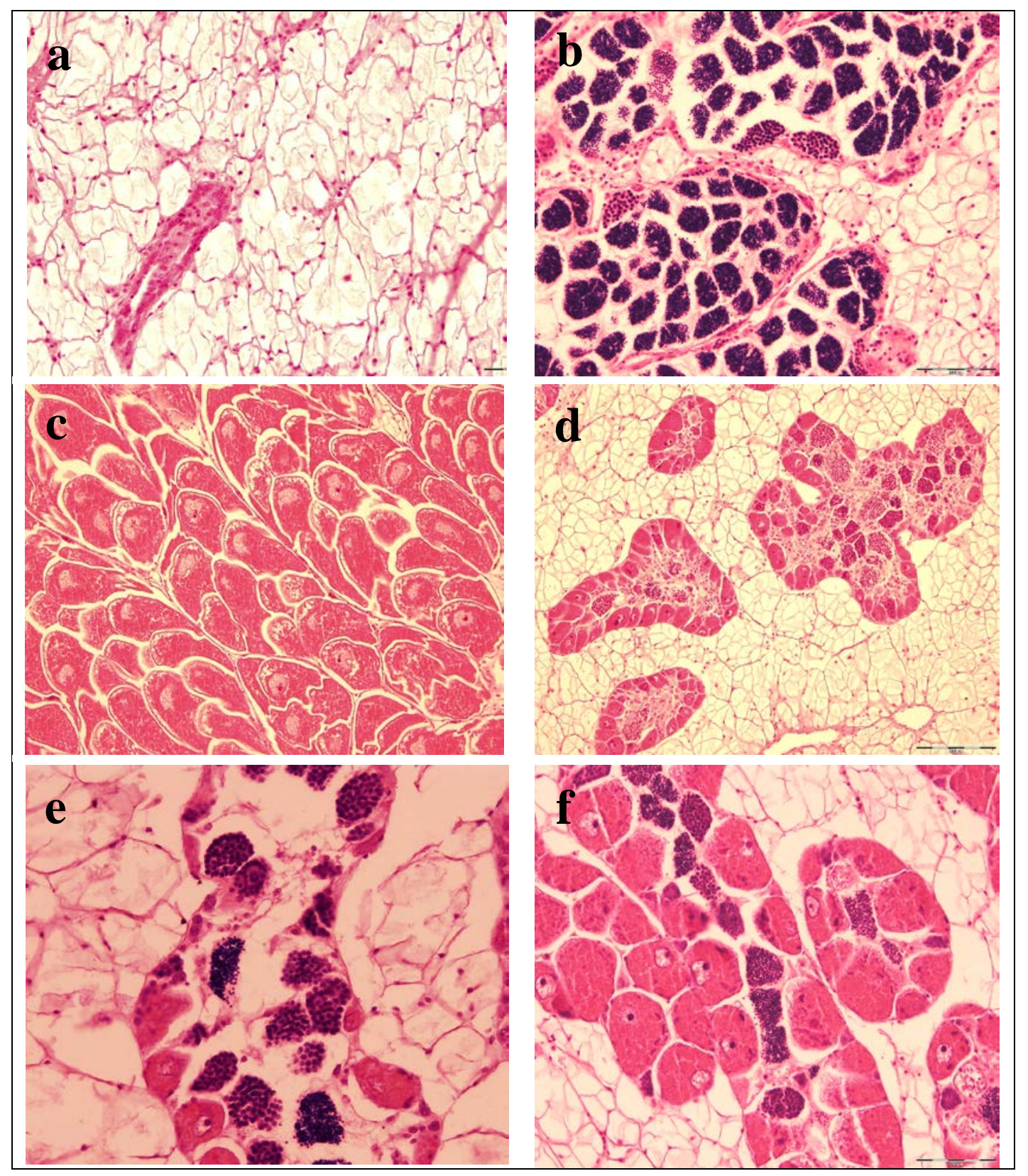


Figure 2
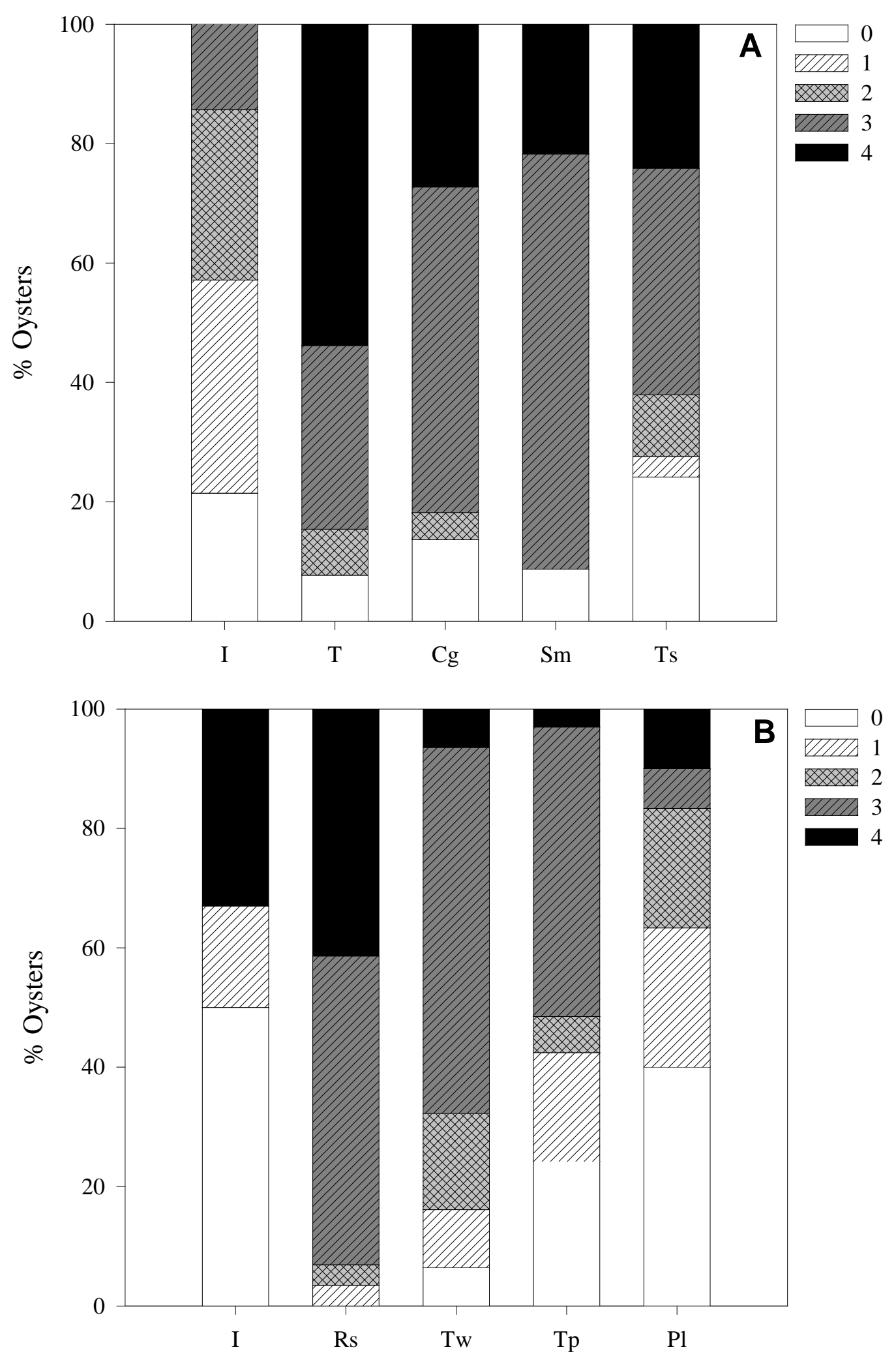